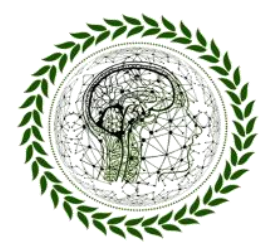

PhI Scientific Review

ISSN 2676 - 0444

Submetido em: 19/10/2021 | Aceito em: 01/11/2021 | Publicado em: 04/11/2021 | Artigo

\title{
APRENDIZAGEM ATIVA: PERSPECTIVAS PARA UMA APRENDIZAGEM CRÍTICA ${ }^{1}$
}

Miriane Timm Morales

César Augusto Costa

\begin{abstract}
RESUMO
A escola, como instituição social, e seus métodos precisam ser compreendidos em seu contexto histórico, social e cultural, tendo em vista o sujeito que desejamos formar e para qual sociedade. Assim sendo, a educação formal, pedagogicamente intencional, essa mesma sociedade parece estar conduzindo-nos a uma resignificação da interação entre educador e educando. Para tanto, o presente trabalho procura apontar definições sobre aprendizagem ativa, como perspectiva metodológica, identificando as suas formas de abordagem, assim como o papel do educador e do educando nesse processo. A partir disso, o presente ensaio objetiva refletir sobre o conceito de aprendizagem ativa, suas definições, como perspectiva metodológica pautada no desenvolvimento de habilidades de pensamento e questionamento, identificando as suas formas de abordagem, assim como o papel do educador e do educando nesse processo. Por fim, o trabalho procura relacionar aprendizagem ativa e abordagem sócio-histórica, traçando um paralelo crítico entre as formas de abordagem.
\end{abstract}

Palavras-chave: aprendizagem ativa; aprendizagem crítica; aprendizagem significativa; metodologia ativa.

\section{ACTIVE LEARNING:}

\section{PERSPECTIVES FOR CRITICAL LEARNING}

\begin{abstract}
The school, as a social institution, and its methods need to be understood in its historical, social, and cultural context, in view of the subject we want to form and for which society. Thus, formal education, pedagogically intentional, this same society seems to be leading us to a resignification of the interaction between educator and learner. To this end, this paper seeks to point out definitions about active learning, as a methodological perspective, identifying its forms of approach, as well as the role of the educator and the learner in this process. From this, the present essay aims to reflect on the concept of active learning, its definitions, as a methodological perspective based on the development of thinking and questioning skills, identifying its forms of approach, as well as the educator's and the learner's role in this process. Finally, the paper seeks to relate active learning and the social-historical approach, drawing a critical parallel between these approaches.
\end{abstract}

Key-words: active learning; critical learning; meaningful learning; active methodology.

1 Trabalho apresentado como requisito parcial para obtenção do título de Pedagoga na Universidade Católica de Pelotas. 


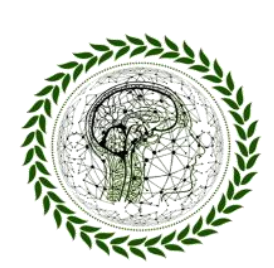

PhID Scientific Review

ISSN 2676 - 0444

\section{Introdução}

A escola, como instituição social, e seus métodos precisam ser compreendidos em seu contexto histórico, social e cultural, tendo em vista o sujeito que desejamos formar e para qual sociedade. Sendo assim, a educação formal, pedagogicamente intencional, essa mesma sociedade parece estar conduzindo-nos a uma ressignificação da interação entre educador e educando. Para tanto, o presente trabalho procura apontar definições sobre aprendizagem ativa, como perspectiva metodológica, identificando as suas formas de abordagem, assim como o papel do educador e do educando nesse processo. Esse trabalho também procura relacionar aprendizagem ativa e abordagem sócio-histórica na perspectiva da Psicologia Histórico-Cultural da Escola de Vigotski (DUARTE, 1996), traçando um paralelo crítico e perspectivas reais.

Os potenciais humanos para uma participação consciente e ativa envolvem o desenvolvimento de habilidades de pensamento, questionamento, desde o início da vida escolar. Como aponta Vickery (2016), a aprendizagem ativa está preocupada com um processo educativo significativo, que envolve controle das crianças sobre si mesmas e de seu mundo para que possam participar plenamente dele. Assim, Bacich e Moran (2018) apontam que o uso da palavra ativa concerne a uma aprendizagem reflexiva, capaz de tornar visíveis os processos, os conhecimentos e as competências que estão sendo desenvolvidas no processo de aprendizagem, entendendo que essa aprendizagem avança de níveis simples para complexos envolvendo todas as dimensões da vida.

Freire e Faundez (2017) defendem uma educação de perguntas como única educação criativa, uma pedagogia da radical pergunta para ser vivida na escola ou na luta política, entendendo que, de modo geral, no processo educativo, no trabalho e no âmbito político, se reproduz o racionalismo abstrato, permeado de autoritarismo, que inibe a pergunta, a criatividade. Haja vista que "A existência humana é, porque se fez perguntando, a raiz da transformação do mundo. Há uma radicalidade na existência, que é a radicalidade do ato de perguntar" (FREIRE, 2017 in FREIRE; FAUNDEZ, 2017, p.75).

Assim, para abordar as questões propostas, o texto está organizado em quatro momentos que se seguem após a introdução. No primeiro momento, buscaremos conceituar os elementos que caracterizam a aprendizagem ativa. No segundo, abordaremos a as formas de

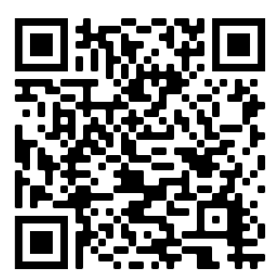

V. 01, $\mathrm{N}^{\mathrm{o}}$ 06, novembro de 2021

Todos os direitos reservados $\odot$ http://www.revistaphd.periodikos.com.br 


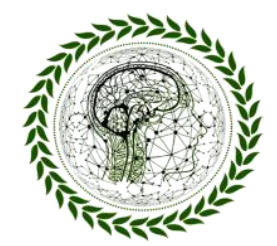

PhD Scientific Review

ISSN 2676 - 0444

aprendizagem ativa. No terceiro, elencaremos as relações entre aprendizagem ativa e a abordagem sócio-histórica. Ao fim, tentaremos relacionar as implicações entre a aprendizagem crítica no que tange ao uso das tecnologias digitais de forma a contribuir na dimensão da cidadania.

\section{Conceituando a aprendizagem ativa}

A aprendizagem ativa, explorada nesse trabalho, trata de abordar os fatores que podem contribuir para transformar crianças em parceiros ativos de sua própria aprendizagem, com vistas a sua emancipação. Tal abordagem pedagógica e curricular advém de pesquisas recentes, sobre como as crianças aprendem, e podem ser detectadas em vários "movimentos" curriculares, como: currículo criativo, aprendizagem ativa, abordagem com base em indagação, personalização, avaliação em prol da aprendizagem, currículo centrado no aluno e novas áreas de atividade como o desenvolvimento de habilidades interdisciplinares de pensamento e aprendizagem (VICKERY, 2016).

Segundo Moran (BACICH; MORAN, 2018), “a vida é um processo de aprendizagem ativa, de enfrentamento de desafios cada vez mais complexos". Porém, “o que constatamos, cada vez mais, é que a aprendizagem por meio da transmissão é importante, mas a aprendizagem por questionamento e experimentação é mais relevante para uma compreensão mais ampla e profunda”. (MORAN, 2018, p.2 apud BACICH; MORAN, 2018, p.2)

A aprendizagem ativa, portanto, não está preocupada apenas com o "fazer" que observamos constantemente nas crianças pequenas, embora estar fisicamente ativo é algo intrínseco ao seu comportamento de aprendizagem. Está profundamente preocupada com a busca das crianças por significado e maestria, com o esforço delas para assumir o controle de si mesmas e de seu mundo e, assim, conseguir participar plenamente dele. (FFIELD, 2016 p.23 apud VICKERY, 2016).

De acordo com Carril, Natário e Zoccal (2018, p.70), a partir da obra de Freire, “o processo de aprendizagem está apoiado em aspectos que demandam significância para o aluno, ou seja, estão associados a um saber já existente e a utilização no seu espaço cotidiano”. Com isso, a aprendizagem significativa e, por conseguinte, ativa, é contextualizada na realidade sociohistórica do educando, onde os saberes desse são considerados como princípio fundamental para todo o processo e sucessiva compreensão dos que conhecimentos que estão sendo aprendidos, atribuindo assim sentido e propósito para transformação.

V. 01, $\mathrm{N}^{\mathrm{o}}$ 06, novembro de 2021

Todos os direitos reservados $\odot$ http://www.revistaphd.periodikos.com.br 


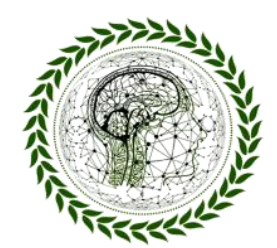

\section{PhI Scientific Review}

ISSN 2676 - 0444

Esse modelo de aprendizagem emancipadora deve acompanhar toda vida escolar do sujeito, como destaca Carril, Natário e Zoccal (2018), de acordo com o pensamento de Freire o processo de aprendizagem da leitura e da escrita é indissociável do aspecto político, ou seja,

O educando é incentivado a refletir sobre a sua história como indivíduo, como pertencente a um grupo social e sobre o lugar que ocupa nesta sociedade, enquanto tem acesso ao desenvolvimento da habilidade de ler e escrever. As discussões realizadas em torno de sua realidade tendem a se aprofundar, o que conduz a uma visão mais concreta e mais ampla. O educando desenvolve um entendimento crítico, constituindose, então, em instrumento de intervenção na realidade, com possibilidade de transformação, diz-se de uma alfabetização em contexto de letramento, com uma função social real (CARRIL, NATÁRIO, ZOCCAL, 2018, p.72).

Para tanto, Freire prevê a passagem de um processo tradicional de aquisição do conhecimento para uma aprendizagem significativa crítica, onde o questionamento tem papel fundamental, pois "quando o aluno formula uma pergunta relevante, apropriada e consistente, ele utiliza seu conhecimento prévio de maneira não-arbitária e substancial, o que evidencia a aprendizagem significativa” (CARRIL, NATÁRIO, ZOCCAL, 2018, p.73).

Segundo apontado pelo filósofo Leandro Karnal, o professor, de modo geral, ainda prática o questionamento no uso de perguntas retóricas que já sabe a resposta e cuja pergunta não é capaz de realmente questionar o aluno, evocando apenas conhecimentos memorizados (KARNAL, 2019 in KARNAL, DUHÁ, 2019). Essa forma de posicionamento do professor vai de encontro com os estudos sobre aprendizagem ativa, visto que não provoca o educando a pensar e questionar a construção histórico-social da humanidade, ou seja, não provoca a disrupção do modelo tradicional de ensino, onde "a realidade não está aí para ser interpretada ou mudada, mas para ser descrita, observada [...] não propõem qualquer intercâmbio crítico entre o sujeito do conhecimento e o objeto a ser conhecido" (SHOR; FREIRE, 1986, p. 36 in CARRIL, NATÁRIO, ZOCCAL, 2018, p.75).

Nesse aspecto, o educador deve praticar e provocar no educando o diálogo freiriano “[...] que não procura descobrir o pré-existente, o já pronto", esse diálogo “[...] se faz pela pergunta que requer reflexão, mas que jamais abandona a intuição sentida, a observação acurada, os sentimentos vividos e a emoção presente e exposta eticamente". Tal como "[...] não é uma simples conversa descompromissada, ou uma conversa sem um fim que não seja a preservação do mais ético que temos e devemos resguardar em nós mesmos”, haja vista que esse “... se

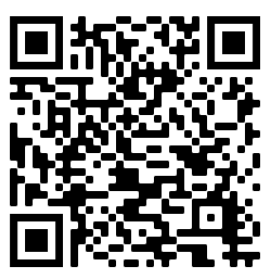

V. 01, $\mathrm{N}^{\mathrm{o}}$ 06, novembro de 2021

Todos os direitos reservados $\odot$ http://www.revistaphd.periodikos.com.br 


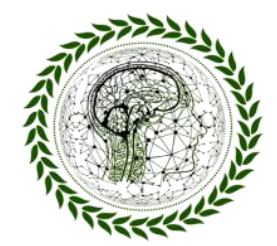

PhI Scientific Review

ISSN 2676 - 0444

propõe a abrir as possibilidades de entender que só lemos um texto se formos lendo o contexto de quem escreveu, relacionando-o com o nosso, o contexto de quem está lendo o texto." (FREIRE, 2015, p.295-297)

Destarte, considera-se essencial, com base em Vickery (2016), para esse modo de ensino, o desenvolvimento das seguintes categorias: (i) habilidades de pensamento; (ii) habilidades de questionamento; (iii) ambiente capaz de oferecer a estrutura necessária para o desenvolvimento e valorização dessas experiências.

Sobre as habilidades de pensamento, Fisher de acordo com Vickery (2016, p.7) indica uma definição aceita, de modo geral, na qual "as habilidades de pensamento são um conjunto de habilidades que capacitam as pessoas a pensar de maneiras diferentes para diferentes fins". Para tanto, o pensamento deve ser incentivado como uma habilidade a ser desenvolvida através do desenvolvimento concomitante da linguagem, ou seja,

O desenvolvimento das habilidades de pensamento se baseia em ser capaz de tornar o pensamento visível. Para fazer isso, claramente será necessário ajudar as crianças a desenvolver uma linguagem que possa ser usada para descrever o pensamento delas. VICKERY (2016, p.8)

No mesmo sentido, aponta Moran (2018, p.3 apud BACICH; MORAN, 2018), “A ênfase na palavra ativa precisa sempre estar associada à aprendizagem reflexiva, para tornar visíveis os processos, os conhecimentos e as competências do que estamos aprendendo com cada atividade". Entendendo que a prática reflexiva:

Envolve uma análise proativa de experiência e baseia-se em um repertório de
competências e experiências, a fim de aprender e evoluir a partir dessa experiência. Essa
é a prática reflexiva que recomendamos para professores e crianças, porque essas
percepções reflexivas lhe permitem crescer e aprender com suas experiências,
identificando e criando as mudanças necessárias para apoiar e desenvolver a
aprendizagem (POLLARD et al., 2008 apud VICKERY, 2016, p.88)

Assim como, faz-se necessário o desenvolvimento das habilidades de questionamento, tanto para o professor como para o aluno. Partindo do pressuposto que a pergunta sugere interesse em aprender algo, nesse contexto o ensino e a aprendizagem envolvem professor e alunos falando e fazendo perguntas, onde "A qualidade dessas interações e o seu impacto na aprendizagem dependerão da qualidade e da eficácia das perguntas e do nível de interesse do aluno.” (VICKERY, 2016, p.68). Nesse mesmo aspecto, Vickery (2016) também sugere o termo

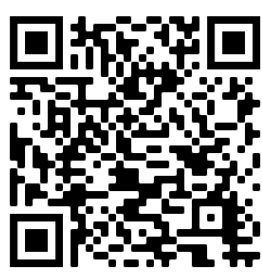

V. 01, No 06, novembro de 2021

Todos os direitos reservados@ http://www.revistaphd.periodikos.com.br 


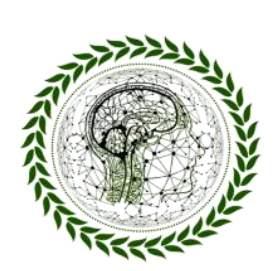

PhID Scientific Review

ISSN 2676 - 0444

"cultura de indagação" que aponta para um ambiente que alcunha desenvolver a curiosidade, a criatividade e o pensamento crítico das crianças. O desenvolvimento dessas habilidades permitirá que as crianças investiguem efetivamente os elementos físicos, sociais e morais do mundo ao redor delas, habilidades essas que serão transferidas para a vida adulta (DUFFY, 2003 apud VICKERY, 2016)

Haja vista a importância do ambiente da sala de aula para o desenvolvimento dessas habilidades de pensamento "[...] esse ensino precisa acontecer em um ambiente de questionamento, debate e descoberta" (VICKERY, 2016, p.9). Esse espaço, que pode ser a sala ou a escola em seus diferentes espaços, devem proporcionar a visibilidade e permanência relativa da trajetória de pensamento e aprendizagem, ou seja, "O ambiente pedagógico deve estar preparado para despertar a curiosidade, o questionamento apoiado na própria realidade dos alunos, assim o trabalho educativo passa a ser feito "para" e "com" o educando" (CARRIL, NATÁRIO, ZOCCAL 2018, p.74).

Em conformidade com Paulo Freire, Schram e Carvalho (s/d, p.3) acreditam "no professor capaz de coordenar a ação educativa; no educando como agente sujeito participante; na escola como currículo de cultura e na sala de aula como espaço de diálogo.” Bem como, de acordo com os autores, a escola deve promover uma proposta de educação "em que as pessoas vão se completando ao longo da vida, capaz de ouvir as pessoas, participando dessa realidade, discutindo-a, e colocando como perspectiva a possibilidade de mudar essa realidade".

Destarte, a discussão em torno do currículo ainda cria oposição entre conteúdo e processo, gerando apreensão entre os educadores quanto a um currículo dirigido ao conteúdo, que não prepara os educandos a serem cidadãos confiantes e com habilidades necessárias para o século XXI (Vickery, 2016). E conforme aponta Schram e Carvalho (s/d), a escola precisa adotar um currículo significativo, com um projeto político pedagógico pautado na educação crítica, para isso, torna-se necessário desenvolver em educadores e educandos a capacidade de agir e refletir sobre a realidade.

Do mesmo modo, Freire em sua obra expõe sua preocupação com a formação permanente, que consiste na reflexão sobre a prática e sobre o projeto político pedagógico que se deseja para a escola. Assim, entendendo o educador como alguém que "consciente de sua 


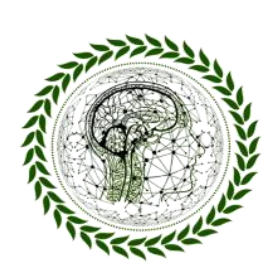

PhI Scientific Review

ISSN 2676 - 0444

responsabilidade, com competência técnica, associa o ensino do conteúdo à leitura crítica da realidade, inquietando os educandos, desafiando-os para que percebam que o mundo pode ser mudado, transformado, reinventado" (SCHRAM; CARVALHO, s/d, p.13).

Entendendo a educação como um processo que não tem início nem fim na escola, mas que se dá ao longo da vida. De acordo com Schram e Carvalho, em Paulo Freire:

[...] a escola é um espaço de encontro, de concepções de vida, de alunos, de professores, de outros igualmente envolvidos e responsáveis. Remete todos à responsabilidade de trabalhar o conteúdo, os conhecimentos, para além da educação bancária que tanto criticou, antes requer em especial dos professores, que busquem ao trabalhar os conhecimentos acumulados, a observância de sua dimensão política e social, e o desenvolvimento de aprendizagens significativas. (SCHRAM; CARVALHO, s/d, p.16)

O incentivo ao pensamento e ao questionamento sugere também que a criança possa posicionar-se no centro das decisões sobre sua aprendizagem, visto que "A aprendizagem ativa torna-se realidade quando as crianças se envolvem no planejamento e na avaliação de sua aprendizagem.” (VICKERY, 2016, p.46). Dessa forma, com o envolvimento das crianças através de sugestões sobre o que devem estudar, torna-se mais provável o aumento da motivação e dedicação.

Nesse aspecto, GANZELA (In: BACICH, TANZI NETO, TREVISANI, 2015, p.47) aponta para "[...] o termo "personalização" como a possibilidade de promover experiências de aprendizagem que atendam, mais proximamente, às necessidades particulares do aprendiz". Essas experiências de aprendizagem personalizadas tornam-se significativas na medida em que

No processo de ensinar e aprender, é fundamental que a construção de sentido seja entrelaçada à construção dos significados. O sentido, o propósito e o objetivo do aprender, para cada um, devem se entrelaçar com os significativos socialmente construídos do conhecimento acumulado nas ciências, na cultura e na tecnologia. (ANDREADE; SARTORI; In: BACICH, TANZI NETO, TREVISANI, 2015, p.183)

Desse modo, as metodologias que se propõem ativas, parecem comprometer-se com estratégias educacionais, ainda que pré-definidas, que podem ser aprimoradas em conjunto. Sobre as condições necessárias para a atives discente Bacich, Tanzi Neto e Trevisani (2013, p.54) apontam que "Em um ambiente de aprendizagem personalizado, o aprendizado começa com o aluno. O aprendiz informa como aprende melhor para que organize seus objetivos de forma ativa, junto com o professor." A sala torna-se um espaço de liberdade, onde os integrantes do 


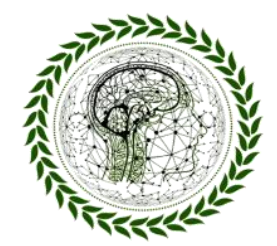

PhD Scientific Review

ISSN 2676 - 0444

processo podem agir em uma dinâmica colaborativa, quanto a relevância de suas intervenções e participações.

Sendo a sala de aula o espaço de provocar formas de intervenção no mundo:

O aprendizado deve ser impulsionado pela curiosidade, pelo interesse, pela crise, pela problematização e pela busca de soluções possíveis para aquele momento histórico com a visão de que não respostas únicas, absolutas e inquestionáveis. (BEHRENS In: MORAN, MASETTO, BEHRENS, 2013, p.91).

A forma como organizamos e conduzimos a prática pedagógica pode provocar a reflexão e o desejo de mudança a partir de uma aprendizagem colaborativa, ou seja, "Os projetos de aprendizagem colaborativa partem do levantamento das aptidões e competências que o professor pretende desenvolver com seus alunos" (BEHRENS, 2013, p.112). A respeito dessas competências, podemos observar o disposto na BNCC (Base Nacional Comum Curricular, 2017) quando aponta para compromisso com a educação integral, que:

Requer o desenvolvimento de competências para aprender a aprender, saber lidar com a informação cada vez mais disponível, atuar com discernimento e responsabilidade nos contextos das culturas digitais, aplicar conhecimentos para resolver problemas, ter autonomia para tomar decisões, ser proativo para identificar os dados de uma situação e buscar soluções, conviver e aprender com as diferenças e as diversidades. (BRASIL, 2017).

A sala de aula, enquanto estrutura e organização física, e o docente, enquanto quem ensina e media o processo de aprendizagem, são responsáveis por proporcionar as condições necessárias para essa aprendizagem colaborativa. Visto que "Os alunos que se envolvem nesses processos de parceria têm a oportunidade de desenvolver competências, habilidades e aptidões que serão úteis à vida toda.” (BEHRENS, 2013, p.136 in MORAN; MASETTO; BEHRENS; 2013).

$\mathrm{Na}$ medida em que a prática do diálogo passa a ser dimensão essencial do processo educativo, o educando passa a ser capaz de refletir sua realidade, assim sendo, a educação crítica consiste na reflexão do ato de existir a partir das experiências do professor e do aluno. Essa leitura da realidade possibilitará, conforme caracteriza Paulo Freire, a passagem da consciência ingênua para a consciência crítica, "Assim, trabalhar para a criticidade é a possibilidade de ação e de participação que só se efetiva na transformação consciente do meio, o qual só pode ser

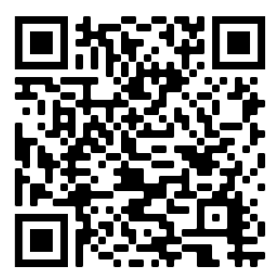

V. 01, No 06, novembro de 2021

Todos os direitos reservados@ http://www.revistaphd.periodikos.com.br 


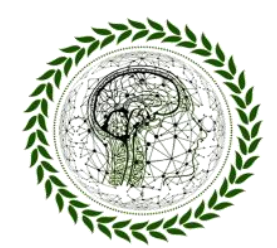

PhI Scientific Review

ISSN 2676 - 0444

transformado com recursos que implicam a participação de todos para a conquista da educação libertadora." (SCHRAM; CARVALHO, s/d, p.6).

Assim como defende Ana Maria Freire, sobre o diálogo pensado por Paulo Freire, que por "[...] sério e rigoroso, nos impede das certezas estreitas e limitantes das interpretações do mundo e da Verdade, e nos introduz no complexo "mundo das possibilidades", dando as aberturas ao mundo da criação, da ousadia e da invenção", só esse "[...] permite ler o texto lendo o contexto". (FREIRE, 2015, p.297)

\section{Formas de abordagem da aprendizagem ativa}

Segundo revisão sistemática realizada por Rückl e Vosgerau (2017), que se utilizou do protocolo de Schiavon (2015) e pressupostos de The Campbell Colaboration (2013), a aprendizagem ativa pode ocorrer através de métodos com ou sem a utilização de dispositivos eletrônicos ou artefatos digitais.

No primeiro caso, sem a utilização de meios eletrônico-digitais, "as estratégias mais utilizadas foram a aprendizagem cooperativa, aprendizagem comunicativa, aprendizagem colaborativa, aprendizagem interativa, aprendizagem baseada em projetos, aprendizagem baseada em problemas, peer-instruction.” (RÜCKEL; VOSGERAU, p.11891, 2017) Segundo apontado pela pesquisa, a implementação de métodos com base na aprendizagem ativa fora dificultada nos contextos onde havia regime cultural tradicionalista no ensino, gestão autoritária e espaço físico precário. Porém, apesar das dificuldades, os resultados foram positivos para os alunos e professores. Visto que se observou participação dos alunos nas atividades, onde as regras de respeito com os colegas foram realizadas, assim como houve interação entre alunos e professores através de experiências, estimulação da prática oral e atividades que proporcionaram a interação entre alunos e professores.

Nos métodos com a utilização dos meios eletrônico-digitais, os principais propósitos apontados têm foco no estímulo motivacional, interação, despertar criativo, modernização de ensino. Nesses métodos verificou-se similaridade quanto às estratégias utilizadas no primeiro caso, diferenciando-se pela utilização conjunta de algum dispositivo eletrônico e das TICs (tecnologias de informação e comunicação). Segundo levantado pelas pesquisadoras, todas as

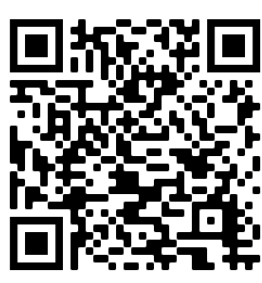

V. 01, $\mathrm{N}^{\mathrm{o}}$ 06, novembro de 2021

Todos os direitos reservados $\odot$ http://www.revistaphd.periodikos.com.br 


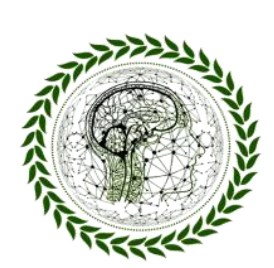

PhI Scientific Review

ISSN 2676 - 0444

propostas, nesse aspecto, apresentaram dificuldades no processo, porém os resultados foram positivos e satisfatórios, com exceção de apenas um caso onde o processo resultou falho para os princípios da aprendizagem ativa. (RÜCKEL; VOSGERAU, 2017)

Sobre as tecnologias digitais, Moran (2018) aponta que essas trazem inúmeros problemas, desafios, distorções e dependências, porém, ainda assim, as tecnologias facilitam a aprendizagem colaborativa, entre colegas próximos e distantes, são fundamentais para a inovação pedagógica quando combinadas com as metodologias ativas.

\begin{abstract}
Os bons materiais (interessantes e estimulantes, impressos e digitais) são fundamentais para o sucesso da aprendizagem. Precisam ser acompanhados de desafios, atividades, histórias, jogos que realmente mobilizem os alunos em cada etapa, que lhes permitam caminhar em grupo (colaborativamente) e sozinhos (aprendizagem personalizada) utilizando as tecnologias mais adequadas (e possíveis) em cada momento (MORAN, 2018, p.12 in BACICH; MORAN, 2018).
\end{abstract}

Ainda sobre as pesquisas de Rückel e Vosgerau (2017), as mesmas apontaram que as metodologias não dependem fundamentalmente do artefato tecnológico, visto que "mesmo com a utilização de um livro e caderno, o mais importante é mudar o conceito e metodologia do professor” (RÜCKEL; VOSGERAU, p.11896, 2017). Visto que, o professor nesse contexto assume um papel muito mais amplo e complexo, que "Não está centrado só em transmitir informações de uma área específica; ele é principalmente designer de roteiros personalizados e grupais de aprendizagem e orientador/mentor de projetos profissionais e de vida dos alunos." ((MORAN, 2018, p.21 in BACICH; MORAN, 2018)

Como apontado por Teixeira e Barca (2019, p.75-76), "Em uma perspectiva dialética, defendida por Vigotski, o professor é o organizador, administrador do meio educativo, o regulador e controlador da interação do meio educativo com cada aluno.” Nessa abordagem, o professor é aquele que organiza o meio social educativo, das relações sociais que ocorrem na escola, dirige o processo educativo com bases científicas, conduzindo a prática educativa de forma intencional. Quanto à característica de mediador, para Vigostki, segundo apontado pelas autoras, “[...] a mediação pedagógica, realizada pelo professor, seria, uma modalidade de mediação simbólica e o mediador não seria o professor, mas a linguagem (sistema de signos) utilizada por ele para mediar semioticamente as relações sociais que se processam na escola.

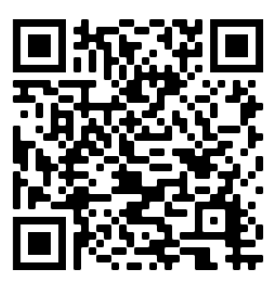

V. 01, No 06, novembro de 2021

Todos os direitos reservados@ http://www.revistaphd.periodikos.com.br 


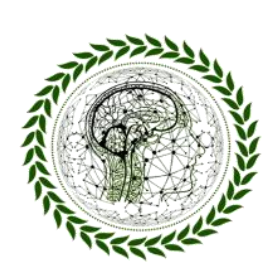

PhI Scientific Review

ISSN 2676 - 0444

Podemos relacionar esse novo conceito ao processo criativo, conforme a observado por Oliveira e Lima (2017), sobre a capacidade criadora propriamente humana, como decorrentes de progressivas transformações na estrutura do cérebro, onde "a competência de produzir, reproduzir, criar e recriar tem como base orgânica a plasticidade das substâncias nervosas, as quais possibilitam o desempenho de funções superiores”. Tais transformações ocorrem em função das influências do meio. (OLIVEIRA; LIMA, p.1400, 2017).

De acordo com Vigotski, em Oliveira e Lima (2017), o ser humano é capaz de combinar e recriar, de projetar-se para o futuro, criando e modificando o seu tempo presente. Portanto, essa concepção, histórico-cultural, acrescenta, à atividade criadora do homem, uma base extracerebral no que concerne a formação das funções psicológicas superiores.

Esse substrato extracerebral é constituído das relações formadas na atividade externa do homem, nas quais se faz uso de instrumentos e signos externos que, ao serem internalizados, reorganizam em novos patamares as funções psicológicas humanas. Mediante essas relações, dos instrumentos e signos, é possível que se tenha acesso àquilo que não foi vivido, experienciado (OLIVEIRA; LIMA, p.1401, 2017).

Para tanto "A arte do debate e da colaboração precisa ser ensinada a fim de ser eficaz em promover a criatividade, bem como em gerar interação e compreensão significativas para o aluno" (SCARDAMALLIA; BEREITER; LAMON, 1994 apud Vickery, p.154, 2016). Conforme apontado por Vickery (2016, p.154), o trabalho colaborativo envolve os quatro métodos mais eficazes de aprendizagem apresentadas na "Pirâmide da Aprendizagem" reproduzida por Koshy, Ernest e Casey (2000) e desenvolvida pelos Laboratório Nacional de Treinamento (National Training Laboratórios, NTL) nos Estados Unidos, esse estudo "mapeia uma gama de métodos de ensino e atividades de aprendizagem em um triângulo na proporção de sua eficácia em promover a retenção, pelo aluno, do material ensinado.” conforme representado na figura 1.

\begin{tabular}{|l|l|}
\hline $\begin{array}{l}\text { Ápice da pirâmide da } \\
\text { aprendizagem }\end{array}$ & $\begin{array}{l}\text { Taxa média de } \\
\text { retenção }\end{array}$ \\
\hline Palestra & $5 \%$ \\
\hline Leitura & $10 \%$ \\
\hline Audiovisual & $20 \%$
\end{tabular}

V. 01, $\mathrm{N}^{\mathrm{o}}$ 06, novembro de 2021

Todos os direitos reservados@ http://www.revistaphd.periodikos.com.br 


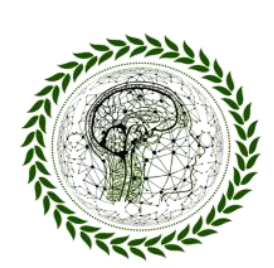

PhI Scientific Review

ISSN 2676 - 0444

\begin{tabular}{|l|l|}
\hline Demonstração & $30 \%$ \\
\hline Grupo de debate & $50 \%$ \\
\hline Praticar fazendo & $75 \%$ \\
\hline $\begin{array}{l}\text { Ensinar aos outros o uso } \\
\text { imediato da aprendizagem }\end{array}$ & $90 \%$ \\
\hline
\end{tabular}

Figura 1: A pirâmide da aprendizagem (tabela organizada pela autora)

Fonte: NTL Institute for Applied Behavioral Science (Vickery, p.154, 2016)

De acordo com Vigotski, em Oliveira e Lima (2017), o ato criador é originário da imaginação, sendo assim, a realidade é seguimento da imaginação e da criação baseada nessa imaginação. Haja vista que o "ato imaginativo compõe-se de elementos tomados da realidade e extraídos da experiência em uma nova combinação" (OLIVEIRA; LIMA, p.1402, 2017). Sendo assim, à escola cabe ampliar a experiência da criança, ao passo que a proporção de elementos da realidade disponíveis à criança está diretamente relacionada com a qualidade e produtividade da imaginação, ou seja, promoverá de forma mais abundante o desenvolvimento da criatividade.

O trabalho colaborativo, visto como experiência de socialização, é promotor da relação entre imaginação e realidade, sendo assim podemos considerar como fundamental para o desenvolvimento da imaginação, ao passo que “[...] a elaboração final da atividade imaginativa corresponde a um fenômeno da realidade e não representa algo irreal". (OLIVEIRA; LIMA, p.1402, 2017)

[...] este poderá imaginar aquilo que nunca viu, poderá, a partir da descrição do outro, representar para si também a descrição daquilo que na sua própria experiência pessoal não existiu, o que não está limitado pelo círculo de fronteira escritas da sua própria experiência, mas pode também ir além das suas fronteiras, assimilando, com a ajuda da imaginação, a experiência histórica e social de outros. Sob essa forma, a imaginação é condição absolutamente necessária de quase toda a atividade intelectual do homem (VIGOTSKI, 2014, p.14 apud OLIVEIRA; LIMA, p.1402, 2017)

\section{Aprendizagem ativa $\mathrm{x}$ abordagem sócio-histórica}

A concepção de homem como um ser sócio-histórico encontra-se na Psicologia Histórico-Cultural, tendo como referência Lev Semenovich Vigotski seguido por outros autores que compõem, através de seus trabalhos, a Escola de Vigotski. (DUARTE, 1996).

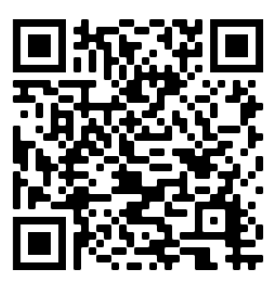

V. 01, No 06, novembro de 2021

Todos os direitos reservados@ http://www.revistaphd.periodikos.com.br 


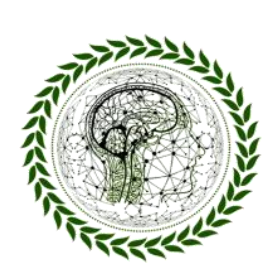

PhI Scientific Review

ISSN 2676 - 0444

Segundo Duarte (1996), a Escola de Vigostski confere ao indivíduo à apropriação da experiência histórico-social, dos conhecimentos produzidos historicamente e já existente no ambiente no qual o indivíduo vive. Assim como, considera os processos de aprendizagem dirigidos pelo educador como superiores aos processos espontâneos de aprendizagem, em termos de qualidade. Haja vista que esses processos se diferenciam, quanto a qualidade, justamente pela presença da intencionalidade na aprendizagem dirigida pelo educador, processo esse que é superior por ultrapassar a pura dependência do que pode ser oferecido objetivamente ao indivíduo pelo meio em que vive.

O autor ainda aponta que, no discurso pedagógico brasileiro, há mais valorização daquilo que o indivíduo constrói por si só do que os conhecimentos adquiridos pela transmissão de outras pessoas (DUARTE, 1996). Nesse sentido, torna-se importante apontar que a perspectiva de aprendizagem ativa aqui exposta não procura dualizar essas formas de apropriação do conhecimento, mas sim reconhecer a relevância do ato de compartilhar conhecimentos, como exposto por Garside (2016, p.198-199 in VICKERY), ao defender a filosofia para crianças como um desejo de "criar um espaço para o seu pensamento e sua indagação e facilitar o caminho para que elas se tornem participantes ativas na sua própria aprendizagem.”, assim “A filosofia para crianças valoriza a comunidade e dá extremo valor ao fato de os indivíduos relatarem seus conhecimentos e compreensões à comunidade.”

Observando o aspecto central na abordagem de Vigotski, sobre as relações entre o ensino e o desenvolvimento intelectual na idade escolar, encontram-se os conceitos de nível de desenvolvimento atual e de zona de desenvolvimento próximo. Verifica-se, através de testes, o que a criança pode resolver de forma independente e assim define-se o nível desenvolvimento atual. Enquanto que na zona de desenvolvimento próximo encontra-se aquilo que a criança não faz sozinha, mas consegue fazer imitando o adulto (DUARTE, 1996 apud Vygotski, 1993, p.23846).

Sendo assim, a aprendizagem ativa concentra-se fundamentalmente na zona de desenvolvimento próximo, é nessa zona onde os professores postulam seus ensinos e assim conseguem trabalhar de forma mais eficaz com os alunos. Através de um trabalho colaborativo, "os alunos conseguem avançar para um trabalho mais independente, "criando andaimes" para a

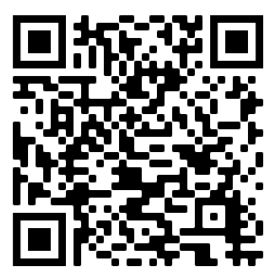

V. 01, $\mathrm{N}^{\mathrm{o}}$ 06, novembro de 2021

Todos os direitos reservados $\odot$ http://www.revistaphd.periodikos.com.br 


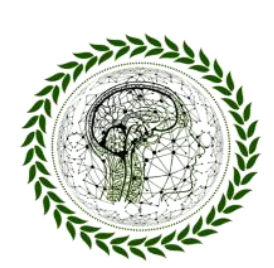

PhI Scientific Review

ISSN 2676 - 0444

sua própria aprendizagem e dos colegas, até que a nova aprendizagem seja internalizada." (DEWCK; LEGGETT, 1988 apud FFIELD APUD VICKERY, 2016, p.32).

$\mathrm{Na}$ mesma podemos observar em Moran (2018, p.2 in BACIH; MORAN), sobre a característica social da apropriação de conhecimentos, "A aprendizagem é ativa e significativa quando avançamos em espiral, de níveis mais simples para mais complexos de conhecimento e competência em todas as dimensões da vida".

Ao abordar o significado de considerar o indivíduo e o conhecimento como essencialmente sociais, Duarte (1996, p.35) expõe, que nessa perspectiva, "Significa, dentre outras coisas, considerar que o indivíduo não pode elaborar seu conhecimento individual a não ser apropriando-se do conhecimento historicamente produzido e socialmente existente". Assim como, "reconhecer a historicidade do ser humano significa, em se tratando do trabalho educativo, valorizar a transmissão da experiência histórico-social, valorizar a transmissão do conhecimento socialmente existente".

Ainda sobre a relação entre desenvolvimento intelectual e aprendizagem escolar, no que diz respeito ao papel desempenhado pelo ensino, "Para Vigotski não é o de esperar que as capacidades necessárias a um determinado conteúdo amadureçam na criança para depois ensinarlhe esse conteúdo. Um ensino que assim proceda vai atrás do desenvolvimento, dirige-se ao seu passado.” (DUARTE, p.39-40, 1996). Nesse sentido, segundo Duarte (1996), a escola deve transmitir à criança os conteúdos historicamente produzidos e socialmente necessários, considerando o que se encontra na zona de desenvolvimento próximo.

A partir da perspectiva de uma aprendizagem ativa, esses conteúdos, que são organizados no currículo, devem pactuar simetricamente o desenvolvimento das habilidades de pensamento e a aquisição de conhecimentos. (VICKERY, 2016). Ou seja,

Todas as disciplinas podem ser abordadas por meio de uma indagação ativa, se a abordagem for valorizada, incentivada e facilitada pelo professor. É importante que as crianças se dediquem ao processo de aprendizagem e reconheçam que os conteúdos podem ser os veículos para a exploração e não apenas fatos a serem absorvidos. (HART et al., 2004 in VICKERY, p.51, 2016). 


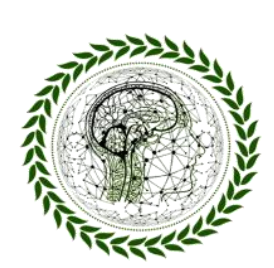

PhID Scientific Review

ISSN 2676 - 0444

\section{Aprendizagem ativa: entre possibilidades e perspectivas críticas}

Em Por uma Pedagogia da Pergunta, Freire e Faundez (2017) apontam para a pergunta como o início do conhecimento, ao colocarmos esse princípio num processo de educação formal aspira-se assim uma disrupção com o modelo tradicional, onde o professor é visto como autoridade, como detentor da verdade, do saber. Essa mudança é possível quando pensamos que “[...] o verdadeiro é uma busca e não um resultado, que verdadeiro é um processo, que o conhecimento é um processo e, enquanto tal, temos de fazê-lo e alcançá-lo através do diálogo, através de rupturas" (FAUNDEZ in FREIRE; FAUNDEZ, p.63,2017).

A pergunta vista como expressão da curiosidade pode às vezes abalar a certeza do professor e ao limitar a curiosidade do aluno o professor autoritário limita a sua também, visto que a pergunta que o aluno faz pode colocar o professor em um ângulo diferente, proporcionando posteriormente uma reflexão crítica. Assim “ $\mathrm{O}$ autoritarismo que corta as nossas experiências educativas inibe, quando não reprime, a capacidade de perguntar. A natureza desafiadora da pergunta tende a ser considerada, na atmosfera autoritária, como provocação à autoridade" (FREIRE in FREIRE; FAUNDEZ, 2017, p.68).

Da mesma forma, as tecnologias digitais e a aprendizagem ativa aparecem abalar o formato de educação autoritária, na medida em que esses meios digitais proporcionam acesso ilimitado ao conhecimento, podem ser vistos como substitutos do professor ou até mesmo da escola. Porém, conforme apontam Lubachewski, Cerutti e Silva (2019, p.3), “A inserção das tecnologias não substituirá o professor, mas possibilitará novas metodologias de ensino, que por sua vez, trarão alternativas e ferramentas que facilitam o ensino-aprendizagem em sala de aula." Dessa forma, o professor poderá mediar o acesso à informação, no sentido de orientar e indicar quanto à fonte e credibilidade desse conteúdo, como mediação dos signos, como quem ensina a pensar e questionar o que está posto.

A aprendizagem ativa, como metodologia de ensino, "proporciona superar os modelos pedagógicos históricos, no qual o estudante assume a condição de expectador que assimila a realidade e os conhecimentos sem refletir, criticar e significa-los." (LUBACHEWSKI; CERUT'TI; SILVA, 2019, p.4). Essa perspectiva aponta para uma metodologia que abranja os meios atuais de 


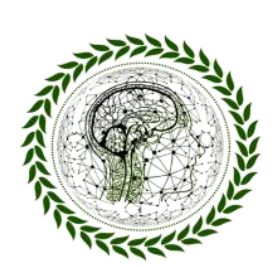

PhID Scientific Review

ISSN 2676 - 0444

acesso ao conhecimento e que seja capaz de ensinar também o aluno a pensar, questionar, perguntar, como processo autorreflexivo e de diálogo.

Trata-se de uma mudança de paradigma sobre o papel da educação formal na sociedade atual, entendendo o sujeito, educando, em sua conjuntura histórica e sociocultural com vistas a sua atives enquanto cidadão. Dessa forma, Andrade (2008, p.3) aponta para a década de 80 como um período de emersão do povo brasileiro como sujeitos políticos, desencadeando uma noção de cidadania ativa que envolve participação popular no controle social das políticas públicas, pois: "As diferentes investidas e pressões das classes subalternas se caracterizam como espaço de educativos, que dentro de uma práxis social vão extraindo novas compreensões e possibilidades de participação na vida social, um alargamento da compreensão dos direitos e um exercício de cidadania ativa (ANDRADE, 2008, p. 3).

Esse período da história constitui uma nova etapa de configuração do capitalismo, com perspectivas neoliberais e de Estado Mínimo, onde a articulação dos setores dominantes diante da ação contra-hegemônica das classes subalternas caracterizava-se pelo uso dos elementos de coerção, inspirado nos períodos ditatoriais, assim como de práticas populistas, onde “[...] as práticas educativas formais e não-formais, exercem um importante papel no ofuscamento dos contrastes e conflitos sociais existentes ou recolocá-lo dentro de um horizonte político-ideológico que não apresenta ameaça substantivas aos interesses de acumulação do capitalismo" (ANDRADE, 2008, p.4).

Nesse sentido, no diálogo entre Freire e Faundez (2017), sobre a racionalidade abstrata no processo de trabalho que repercute no processo educativo, Freire (2017 in FREIRE; FAUNDEZ, 2017 p.78) aponta que "embrutecer a força de trabalho submetida a procedimentos rotineiros faz parte da natureza do modo de produção capitalista. O que se dá na produção do conhecimento na escola é, em grande parte, mesmo que possamos fazer o contrário, a reprodução desse mecanismo". Faundez (2017 in FREIRE; FAUNDEZ, 2017 p.78) complementa apontando que:

Sim, é a racionalidade abstrata que impõe um poder determinado de uma ideologia determinada. Sem dúvida, é muito difícil escapar a isso. O que se reproduz num processo educativo, tanto no trabalho como nas escolas, se reproduz também no âmbito político, no processo político, que é também um grande processo educativo, no qual a criatividade das massas é ignorada, é esmagada!".

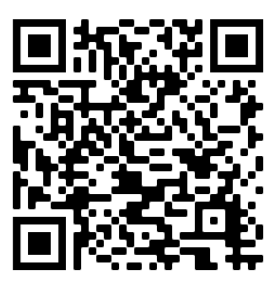

V. 01, $\mathrm{N}^{\mathrm{o}}$ 06, novembro de 2021

Todos os direitos reservados $\odot$ http://www.revistaphd.periodikos.com.br 


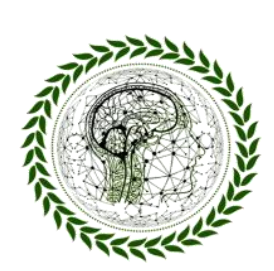

PhI Scientific Review

ISSN 2676 - 0444

É para o exercício da cidadania que se faz necessária uma pedagogia que ensine a pensar de forma crítica, a questionar a construção histórico-social do conhecimento, das relações sociais, dos mecanismos de dominação político-econômicos, visto que, se trata de "[...] uma pedagogia em cuja prática não há lugar para a dicotomia entre sentir o fato e apreender a sua razão de ser." (FAUNDEZ in FREIRE; FAUNDEZ, 2017, p.83).

A pedagogia aqui proposta não se pensa a partir de uma oposição radical aos métodos tradicionais de aprendizagem, haja vista que nossa formação foi em grande parte ainda permeada por traços desse modelo, principalmente no que concerne a educação básica. No entanto, através de uma abordagem ativa de aprendizagem, criticamos a obediência e submissão autoritária ainda praticada nas escolas de forma consciente ou inconsciente e lançamos olhar para perspectivas pedagógicas que procuram desenvolver a autonomia dos educandos, entendendo que o professor “... tanto pode contribuir para a promoção de autonomia dos alunos como para manutenção de comportamentos de controle sobre os mesmos” (BERBEL, 2011, p.26).

Como aponta Berbel (2011, p.28), “o professor deve adotar a perspectiva do aluno, deve acolher seus pensamentos, sentimentos e ações, sempre que manifestados, e apoiar o seu desenvolvimento motivacional e capacidade para autorregular-se." Dessa maneira, esse comportamento profissional deve ser refletido como essencial para a formação de futuros profissionais nas mais diversas áreas, que através das metodologias ativas "[...] pode vir a favorecer uma motivação autônoma quando incluir o fortalecimento da percepção do aluno de ser origem da própria ação" (BERBEL, 2011, p.28).

Dessa forma, a Pedagogia, como ciência da educação, deve partir do concreto e, mediada pelo conceito, retornar ao concreto, entendendo que o concreto está no processo educativo, na narrativa dos alunos, na sua vivência e realidade. Para Faundez (2017 in FREIRE; FAUNDEZ, 2017 p.95), "isto significa uma revolução, pois se trata de uma nova concepção da ciência como mediadora para a compreensão e transformação da realidade”. Assim sendo, "educar para a autonomia significa também, consequentemente, um ato político e para o campo de formação profissional e ou formação de professores, um ato político pedagógico" (BERBEL, 2011, p.30).

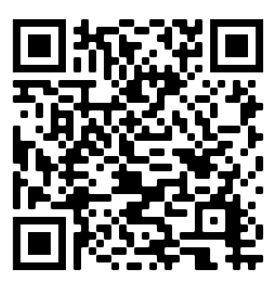

V. 01, No 06, novembro de 2021

Todos os direitos reservados@ http://www.revistaphd.periodikos.com.br 


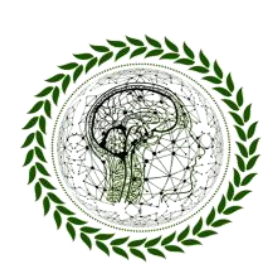

PhI Scientific Review

ISSN 2676 - 0444

\section{Referências}

ANDRADE, Edinaldo C. de. Paulo Freire e a educação para a cidadania: a contribuição crítica da pedagogia libertadora frente ao discurso da educação cidadã a partir dos anos 90 . VI Encontro Internacional do Fórum Paulo Freire, 2008. Disponível em: http://www.acervo.paulofreire.org:8080/jspui/bitstream/7891/4196/1/FPF PTPF 01 0854.p df Acesso em: 10/11/2019.

BACICH, Lilian; TANZI NETO, Adolfo; TREVISANI, Fernando de M. Ensino Híbrido: personalização e tecnologia na educação. Porto Alegre: Penso, 2013.

BACICH, Lilian; MORAN, José. (Orgs.). Metodologias ativas para uma educação inovadora: uma abordagem teórico-prática. Porto Alegre: Penso, 2018.

BERBEL, Nuesi Aparecida N. As metodologias ativas e a promoção da autonomia de estudantes. Semina: Ciências Sociais e Humanas, Londrina, v.32, n. 1, p.25-40, jan./jun.2011.

BRASIL. Ministério da Educação. Base Nacional Comum Curricular. Brasília: MEC, 2017.

CARRIL, Maria da Graça P.; NATÁRIO, Elisete G.; ZOCCAL, Sirlei I. Considerações sobre a aprendizagem significativa, a partir da visão de Freire e Ausubel - uma reflexão teórica. e-Mosaicos - Revista Multidisciplinar de Ensino, Pesquisa, Extensão e Cultura do Instituto de Aplicação Fernando Rodrigues da Silveira (CAp - UERJ) V.6 - N. 13, 2017 - Dezembro.

DUARTE, Newton. A escola de Vigotski e a educação escolar: algumas hipóteses para uma leitura pedagógica da psicologia histórico-cultural. Psicologia USP, São Paulo, v.7, n.1/2, 1996, p.17-50.

FREIRE; Paulo; FAUNDEZ, Antonio. Por uma pedagogia da pergunta. Rio de Janeiro/São Paulo: Paz e Terra, 2017. p.8-90.

FREIRE, Ana Maria A. A leitura do mundo e a leitura da palavra em Paulo Freire. Cad. Cedes, Campina, v. 35, n.96, 2015, p. 291-298, maio-ago.

KARNAL, Leandro; DUHÁ, André H. Curso de extensão mentalidade de desenvolvimento contínuo, PUC-RS, 2019.

LUBACHEWSKI, Gesseca C.; CERUTTI, Elisabete; SILVA, Alexandre da. Aprendizagem ativa e tecnologias digitais: caminhos para potencializar as aprendizagens dos alunos no ensino superior. (2019). Anais do X Congresso Ibero-Americano de Docência Universitária (CIDU). Porto Alegre: EDIPUCRS, 2019. Disponível em:

http://editora.pucrs.br/acessolivre/anais/cidu/assets/edicoes/2018/arquivos/81.pdf Acesso em: 10/11/2019.

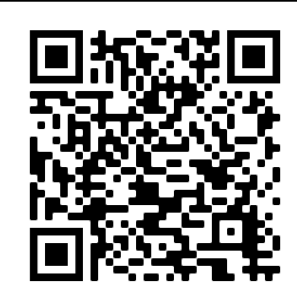

V. 01, No 06, novembro de 2021

Todos os direitos reservados@ http://www.revistaphd.periodikos.com.br 


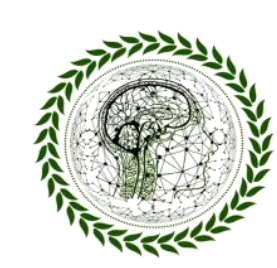

PhI Scientific Review

ISSN 2676 - 0444

MORAN, José Manuel; MASETTO, Marcos T.; BEHRENS, Marilda Aparecida. Novas tecnologias e mediação pedagógica. 21a ed. Campinas: Papirus, 2013.

OLIVEIRA, Artur Bruno F.; LIMA, Ana Ignez B. Vigotski e os Processos Criativos de Professores ante a Realidade Atual. Educação \& Realidade, Porto Alegre, v.42, n.4, 2017, p.1399-1419, out./dez HTTP://dx.doi.org/10.1590/2175-623662025

RÜCKL, Bruna de Fátima N.; VOSGERAU, Dilmeire S. R. Perspectivas da aprendizagem ativa no ensino fundamental: uma revisão sistemática. EDUCERE: XIII Congresso Nacional de Educação, 2017. Acesso em 10 nov. 2019. Disponível em < https://educere.bruc.com.br/arquivo/pdf2017/23881 12578.pdf>

SCHRAM, Sandra Cristina; CARVALHO, Marco Antonio B. O pensar educação em Paulo Freire. Disponível em: http://www.diaadiaeducacao.pr.gov.br/portals/pde/arquivos/852-2.pdf Acesso em: 11/11/2019.

VICKERY, Anitra. Aprendizagem ativa: nos anos iniciais do ensino fundamental. Porto Alegre: Penso, 2016 